\title{
Aristóteles e a possibilidade da mudança de caráter
}

\author{
João Hobuss \\ joao.hobuss@gmail.com \\ Universidade Federal de Pelotas (UFPel), Pelotas, Brasil, CNPq
}

resumo No livro dois da Ética Nicomaqueia, Aristóteles afirma com clareza que a prática reiterada de ações virtuosas leva à constituição de uma determinada disposição de caráter, ou seja, o hábito funcionaria como uma segunda natureza, em função da fixidez e estabilidade da disposição por ele constituída, o que aparentemente impediria qualquer modificação no que concerne ao caráter. 0 problema é que várias passagens do Corpus Aristotelicum parecem contradizer esta asserção, permitindo uma leitura diferente daquela que sugeriria a ideia do hábito como algo que operasse de modo similar à natureza. Este artigo propõe-se investigar se é possível uma leitura que permita, nas Éticas, bem como em outras obras do Corpus Aristotelicum, a possibilidade da mudança de caráter, da decadência ou da reforma moral, bem como sua implicação na investigação sobre o problema do determinismo e da responsabilidade moral.

palavras-chave hábito; disposição de caráter; responsabilidade moral; determinismo; Aristóteles; Ética Nicomaqueia

\section{0 modo pelo qual adquirimos a virtude moral}

É deveras reconhecido o modo pelo qual Aristóteles concebe a aquisição da virtude moral. Ele delineia seu argumento no segundo livro da Ética Nicomaqueia, onde afirma que a virtude moral é adquirida pela prática reiterada de ações virtuosas, ou seja, pelo hábito (1103a17) de agir de determinada maneira, diferentemente da virtude intelectual cuja aquisição tem origem no ensinamento. 
É neste sentido que ele indica o caso próprio das faculdades sensitivas, ressaltando o fato de que primeiro as possuímos, depois as exercitamos (1103a26-30). O caso da virtude dá-se em sentido inverso, pois as adquirimos exercitando-as, como no caso do homem justo, que adquiriu a virtude da justiça, praticando atos justos, ou do temperante que adquiriu a virtude que lhe é peculiar ao efetuar atos temperantes (1103b1-2).

Deste modo, a prática reiterada de atos virtuosos ou viciosos engendrará uma disposição de caráter virtuosa ou viciosa, pois “as disposições originam-se de atividades similares" (1103b21-22). Daí a necessidade imperiosa de habituar os indivíduos desde cedo, pois da prática de hábitos bons ou maus resultará que nos tornemos virtuosos ou viciosos, na medida em que, se não fosse o caso, "ninguém precisaria do mestre, mas todos nasceriam bons ou maus" (1103b10-12). Nascer bom ou mau é uma impossibilidade no que concerne a Aristóteles, pelo simples motivo de que as "as virtudes não se engendram nem naturalmente nem contra a natureza, mas, porque somos naturalmente aptos a recebê-las, aperfeiçoamo-nos pelo hábito" (1103a23-26).

Torna-se evidente que para Aristóteles a virtude moral não é inata, isto é, não se dá por natureza, "pois nada do que existe por natureza habitua-se a ser diverso” (1103a18-20). Assim, a pedra não poderia contrariar sua característica natural de mover-se para baixo, ou o fogo sua característica natural de mover-se para cima. O que ocorre por natureza não é modificado pelo hábito. Logo, o indivíduo é levado pelo hábito a adquirir uma dada qualidade, uma dada disposição de caráter.

Bem, se a virtude moral, contrariamente à pedra e ao fogo, não é engendrada naturalmente, ela, em tese, poderia estar suscetível à corrupção, à perda da qualidade moral que foi adquirida, o que resultaria em uma possível mudança no que concerne às disposições de caráter. Estaria aberta a possibilidade de que o bom se tornasse mau, e de que o mau se tornasse bom, o que permitiria uma leitura da ética aristotélica que contemplasse dois aspectos, (i) a decadência/queda moral e (ii) a reforma ou conversão moral. Entretanto, isto não é de modo algum evidente em Aristóteles, pois existem passagens que negam peremptoriamente tal possibilidade. ${ }^{1}$ Podemos citar dois exemplos claros:

(a) Na EN III 7 (1114a9-21), Aristóteles ressalta que uma vez adquirida uma dada qualidade de caráter não será possível perdê-la: ao injusto 
e intemperante era possível, no início, não se tornar injusto ou intemperante: "Porém, aos que se tornaram injustos ou intemperantes, não lhes é mais possível não o serem";

(b) $\mathrm{Na} E N V 1^{2}$, ao discutir a justiça (dikaiosunê), Aristóteles afirma a existência de uma distinção entre as disposições de caráter, as ciências e as potencialidades ${ }^{3}$, na medida em que há uma única potência, bem como uma única ciência, para os contrários, o que não é o caso para as disposições concernentes ao caráter, pois essas últimas, ao produzirem um determinado efeito, não poderão produzir um efeito contrário.

Este tipo de argumentação parece de algum modo coerente com a afirmação que encontramos em VII 1152a32-33: "Eu te digo, meu amigo: o treinamento exige muito tempo, e a partir deste momento, para os homens, ele [o hábito] termina por ser sua natureza". ${ }^{4} \mathrm{O}$ hábito funcionaria então como uma segunda natureza, similar à natureza, dada sua fixidez e estabilidade. Neste mesmo diapasão surge uma passagem da Retórica: "Pois isto ao que se está habituado torna-se a partir daí como alguma coisa de natural. O hábito, com efeito, tem semelhança com a natureza (...)" 5 .

Se estas passagens são tomadas como o núcleo duro da concepção aristotélica acerca do modo de aquisição e posse da virtude moral, teríamos uma boa pista no sentido de atribuir à ética aristotélica um viés claramente determinista. ${ }^{6}$ Seria este realmente o caso? E, se fosse, como poderíamos ainda lidar de maneira plausível com a discussão a respeito da responsabilidade moral? Se o hábito gera uma disposição de caráter que opera como uma segunda natureza, similar mesmo à natureza, como vimos, de que modo atribuir responsabilidade ao agente moral por sua ação?

Mas não parece ser possível que o núcleo duro da ética aristotélica nos encaminhe para um determinismo tout court. Se as passagens supracitadas tornam aparentemente ingrata a tarefa, é contudo possível dispor de outras que parecem indicar, para a surpresa do leitor, um caminho inverso. Poderíamos lembrar duas delas:

(c) Na ENVII 1152a28-30, Aristóteles afirma que "os incontinentes por natureza são mais dificeis de endireitar do que os incontinentes por hábito". Ora, isto sugere, ao menos em um primeiro olhar, a ideia de conversão ou reforma moral; 
(d) no livro IX 1165b13-14, onde Aristóteles indaga, ao tratar da amizade, se alguém que aceita um amigo porque ele é bom (agathon), mas que se torna perverso (mokhthêros), deve ainda permanecer amigo deste último. Podemos ler esta passagem, e assim o faz Irwin, como veremos adiante - contrariamente a Bodéus ${ }^{7}$ - no seu comentário à EN, em termos de mudança [da disposição] de caráter.

É necessário, por conseguinte mostrar que (a) e (b) podem ser lidas coerentemente com (c) e (d) pois, estas últimas, se não renegam por completo o viés determinista, ao menos o atenuam e possivelmente redimem a possibilidade da imputação moral. Antes de tentar tornar consistente, se isto é possível, a visão aristotélica sobre o assunto, é interessante a abordagem de comentadores gregos antigos, bem como de comentadores contemporâneos sobre o tema.

\section{0 problema nos comentadores antigos de Aristóteles}

Uma tentativa válida no sentido de elucidar o problema é buscar na tradição aristotélica uma coerência acerca do problema, ou se há, ao contrário, uma divergência entre os principais comentadores, bem como, talvez, uma resposta plausível à questão da possibilidade da mudança de caráter. Isto é passível de ser feito através, por exemplo, de Teofrasto. Nos seus fragmentos éticos são encontrados vários argumentos a favor da tese acerca da possibilidade da mudança de caráter. $\mathrm{O}$ que deve ser indagado, por precaução, é se é correto vincular estes argumentos ao discurso moral de Aristóteles. É necessário, então, observar os argumentos contidos nos fragmentos:

(i) em uma passagem de Simplício $^{8}$, uma concepção atribuída a Nicostrato é realçada, qual seja, um homem bom não pode tornar-se mau, o que não é aceito por Teofrasto, que afirma ser "imprudente afirmar que a virtude não pode ser perdida", o que teria sido suficientemente provado pelo mesmo. Esta posição de Teofrasto coincidiria com a de Aristóteles, na medida em que este não aceitaria que algo pudesse ser, e é o caso da virtude, impossível de perder. Tal característica, ou seja, a "imperdibilidade", não pertence ao humano; 
(ii) Plutarco", citando Teofrasto, afirma que este "na sua Ética, levanta a questão se os traços de caráter mudam em resposta à desventura, e sendo mudados por afecções corporais eles cessam de ser virtuosos";

(iii) Cícero $^{10}$, relatando as palavras de Piso, credita a este a defesa de que todos os sábios são felizes de forma continuada. Cético no que se refere às impressões de Piso, Cícero teme que a verdade possa estar no que Teofrasto sustenta "sobre a desventura, o sofrimento, a aflição corporal, os quais ele pensa serem incompatíveis com a vida feliz". Ora, para Teofrasto, é absolutamente inconcebível que um mesmo indivíduo seja "feliz e oprimido por muitos males" (eundem beatum esse et multis malis oppressum), pois essas condições não devem ocorrer simultaneamente;

(iv) $\mathrm{O}$ mesmo Cícero ${ }^{11}$ relata que Teofrasto, de certo modo, "quebrou a autoridade do antigo sistema até mais violentamente (vehementius etiam fregit quodam modo auctoritatem veteris disciplinae $)^{12}$, pois ele pilhou a virtude de sua beleza e tornou-a fraca, negando que a vida feliz esteja situada apenas nela" (spoliavit enim virturem suo decore imbecillamque reddidit quod negavit in ea sola positum esse beate vivere $)^{13}$;

(v) Ainda Cícero ${ }^{14}$ : "O caso dos peripatéticos foi bem esclarecido, exceto por Teofrasto e qualquer outro quem, seguindo ele, com covardia responde à dor com medo e susto" (et Peripateticorum quidem explicata causa est praeter Theophrastum et si qui illum secuti imbecillius horrent dolorem et reformidant), diferentemente dos outros peripatéticos que louvam a virtude, pois quem está de posse desta, mesmo submetido a certos males, é feliz. O "exceto por Teofrasto" pode ser discutido, porque não devemos esquecer que ele é o sucessor de Aristóteles, tendo um peso maior em relação aos outros peripatéticos.

A posição de Teofrasto é bastante clara, pois a leitura dos fragmentos acima citados indica de modo evidente que a virtude pode ser perdida e que o caráter é passível de mudança. Mas isto é claro tão-somente no que se refere a Teofrasto, já que os argumentos desenvolvidos nos fragmentos não somente apontam para a fragilidade da virtude, para a mutabilidade do caráter, bem como para a efemeridade da felicidade. Isto mostra realmente a coerência de Teofrasto, mas talvez não sirva de modo consistente para esclarecer o propósito deste artigo, pois a investigação sobre a mudança de caráter a partir de um representante da tradição aristotélica lança mais sombras do que luz sobre a mesma, pois quando se observa mais 
detidamente os cinco fragmentos é notório o fato de que os fragmentos 497 e 499 apontam para uma dissidência, um forte rompimento entre a tradição acima mencionada e a posição de Teofrasto. Este rompimento, ou a denominada quebra de autoridade do antigo sistema, desaparece completamente no fragmento 462, onde há uma coesão de intenções e concepções entre Teofrasto e Aristóteles, na medida em que há uma clara alusão, a partir do testemunho de Simplício, que, para ambos, seria premeditado sustentar que a virtude não poderia ser perdida. Se a virtude pode ser perdida, o caráter pode mudar. $\mathrm{O}$ modo pelo qual o caráter pode mudar não aparece de maneira consistente, nem no fragmento 462, nem nos outros fragmentos, pois nestes a perda da virtude e da felicidade, bem como a mudança de caráter estão associadas às desventuras da vida ou à doença. De que forma as desventuras ou doenças modificam o caráter não fica esclarecido: por qual razão as desventuras ou as doenças têm esta implicação moral?

De qualquer modo, o fragmento mais direto, e que vincula Teofrasto a Aristóteles, o 462, parece indicar a possibilidade de degradação moral. Sendo assim, é necessário buscar passagens em Aristóteles que confirmem, ou ao menos indiquem, alguma consonância entre o fragmento e as intenções deste último.

$* * *$

No De Fato, Alexandre de Afrodisia ao especificar os argumentos acerca do determinismo, busca solucionar, nos capítulos XXVI-XXIX e XXXII, o problema da compatibilidade entre o determinismo e a responsabilidade moral.

No capítulo XXVI ${ }^{15}$, ele menciona aqueles que argumentam no sentido de que se as coisas dependem de nós (to eph'hêmin $)^{16}$, e em relação às quais podemos fazer o contrário - sendo motivo de louvor e censura -, nem a prudência, nem a virtude, dependerão dos que as possuem, pois neste caso eles não poderão mais admitir vícios contrários às virtudes, da mesma forma que o mau não poderá deixar de sê-lo, pois isto não estaria em seu poder. Ora, afirma Alexandre respondendo aos estoicos, “é absurdo afirmar que as virtudes e os vícios não dependem de nós, e são 
objeto de louvor e censura. Pois não é deste modo que se define o que depende de nós"17.

A solução apontada por Alexandre contra os que afirmam que a virtude e o vício são incontornáveis, isto é, não podem mais serem perdidos, é sublinhar o fato de que as disposições (hexeis) dependem dos que as possuem, pois “antes de as adquirirem, estava em seu poder também não adquiri-las" 18 , na medida em que os que adquiriram a virtude ou o vício são a causa de sua aquisição, pois a geração disto depende completamente de nós ${ }^{19}$.

Neste sentido, é evidente para Alexandre de Afrodisia que estava em nosso poder, antes de tornarmo-nos virtuosos, não sermos virtuosos, o que sugere ser também o caso do vicioso que, antes de sê-lo efetivamente, poderia também não sê-lo. Mas, uma vez que nos tornamos virtuosos ou viciosos, ou seja, adquirimos uma determinada disposição de caráter, fruto da prática reiterada de ações virtuosas ou viciosas ${ }^{20}$, não poderemos mais deixar de sê-lo [virtuoso ou vicioso]. Isto porque o caráter do homem tem origem no hábito de fazer isto ou aquilo, mas uma vez adquirida a disposição, ela está permanentemente fixada. Por conseguinte, a aquisição da virtude [ou do vício] depende de nós ${ }^{21}$.

Logo, está em poder do homem prudente ser prudente, já que ele é a causa própria de sua disposição de caráter ${ }^{22}$, ressaltado o fato de que ele poderia ser a causa, antes de tornar-se prudente, de uma outra disposição de caráter, pois isto dependia, essencialmente, dele.

O problema que surge da argumentação de Alexandre de Afrodisia é como conciliar aquilo que depende de nós, ou seja, a possibilidade de agir diferentemente no processo de aquisição da virtude ou do vício, com a fixidez da disposição de caráter adquirida, não mais passível de mudança. Como atribuir ao agente a responsabilidade moral, se já não há a possibilidade de agir diferentemente? A solução encontrada por Alexandre é a chamada "transitividade da responsabilidade", ou seja, em dado momento o agente podia escolher entre contrários. A partir do momento em que a disposição de caráter foi adquirida não posso mais agir contrariamente a tal disposição, mas preservo a minha responsabilidade moral, pois coube a mim escolher os atos que constituíram a minha disposição, fazendo com que haja uma transferência "ao meu atual estado disposicional" 23 , das escolhas que fiz no processo de aquisição da disposição de caráter. 
A questão é saber se essa solução pode ser, também, atribuída a Aristóteles. Obviamente, Alexandre tem em mente, ao tratar de tema tão espinhoso, a ética aristotélica e a já mencionada potência de contrários, pois este é um problema central em Aristóteles, já que, como foi especificado anteriormente, a tensão entre a possibilidade de agir diferentemente e a ideia de uma disposição de caráter que opera como uma segunda natureza - gerando uma fixidez e estabilidade que impediria de agir de outro modo, uma vez adquirida tal disposição -, parece emergir da leitura de várias passagens do Corpus Aristotelicum.

Não é evidente que a "transitividade da responsabilidade" possa ser atribuída a Aristóteles, mas é necessário investigar se esta solução é plausível para responder a tensão entre a possibilidade de agir diferentemente e a fixidez suposta pela disposição de caráter, bem como sobre um possível determinismo aristotélico e a questão da responsabilidade moral ${ }^{24}$.

Em todo caso, em Alexandre de Afrodisia, que transita no interior da tradição aristotélica, uma vez adquirida uma dada disposição, não é possível mais agir diferentemente - posição distinta da de Teofrasto, ao menos no que se refere ao fragmento 462 -, embora, na sua perspectiva, ainda seja permitida a atribuição de responsabilidade moral ao agente, responsável pela aquisição de sua disposição de caráter.

\section{0 problema nos comentadores contemporâneos}

Uma posição que vai atribuir um tipo de "determinismo mecanicista" à ética aristotélica pode ser encontrada em D. J. Furley. Furley observa que Aristóteles reivindica que o indivíduo que adquire uma determinada disposição de caráter é moralmente responsável pela aquisição desta disposição, na medida em que esta é o resultado da efetivação de ações praticadas repetidamente em certa direção (FURLEY, 1977, p. 50). A prática destas ações é voluntária, sendo, por conseguinte, consequência do caráter do agente, já que Aristóteles atribui a constituição do caráter ao agente ${ }^{25}$. Tendo como pano de fundo esta análise, Furley apresentará a seguinte inferência:

Parece existir aqui uma distinção entre dois períodos da vida de um homem na teoria aristotélica (...) antes e depois da formação de cada disposição particular (hexis), pois o caráter (estou assumindo) é 
simplesmente a soma das disposições de um homem (...) Antes que a disposção de um homem esteja formada, ele está aparentemente 'em uma posição' (kurios) de agir diferentemente. Uma vez que a disposição esteja formada, contudo, isto não é mais verdadeiro. Mas nada é dito a respeito do primeiro estágio" (FURLEY, 1977, p. 50).

Furley corrobora esta posição citando a passagem na qual Aristóteles argumenta que uma vez que o injusto e o intemperante tornaram-se tal, e isto voluntariamente, não poderão mais deixar de sê-lo (1114¹9-21). Por conseguinte, teríamos um estágio no qual o homem adquiriria sua disposição de caráter, podendo, neste momento escolher alternativas contrárias, ou seja, poderia agir diferentemente, e um outro em que isto não seria mais possível dada a fixidez e estabilidade da disposição adquirida. Por conseguinte estaria completamente fechada ao vicioso a possibilidade da redenção moral, pois este seria, sem mais, incorrigível (FURLEY, 1977, p. 51). Mas esta constatação seria um tanto descabida, conforme Furley, pois a finalidade da ética, para Aristóteles, é tornar os homens melhores. $\mathrm{O}$ problema é que no momento em que Aristóteles compara o incontinente e o intemperante, ele afirma que este último, que faz o mal deliberadamente [por não conhecer o bem], diferentemente do incontinente, é, na realidade, incorrigível ${ }^{26}$.

Este tipo de raciocínio, se realmente podemos atribuí-lo a Aristóteles, elimina da concepção de ato voluntário uma série de condições que poderiam, em princípio, serem absolutamente relevantes. Sendo assim, nas palavras de Furley, "uma ato é voluntário se procede de uma disposição que é voluntária” (1977, p. 51), desconsiderando possibilidades que atenuariam, ou mesmo restringiriam fortemente, uma acusação de determinismo no que se refere à ética aristotélica, tal como a possibilidade de agir diferentemente, já que poderíamos vaticinar que o injusto, diante da possibilidade de causar dano, não poderia agir de modo diferente, ou seja, ele perpetrará o dano de forma incondicional. Aparentemente, as ações que poderiam ser ditas 'livres' seriam as realizadas antes da constituição do caráter do indivíduo. Seriam tão somente as ações do indivíduo que formariam sua disposição de caráter, ou seja o indivíduo é a fonte, ou princípio, de suas ações (FURLEY, 1977, p. 53): estas ações e disposições são voluntárias ${ }^{27}$. 
É a conclusão de Furley, que estranha a ausência de menção da parte de Aristóteles de influências externas no que concerne à formação do caráter, como a disciplina imposta pelos pais, professores, bem como o papel do ambiente na formação do mesmo, o que seria ressaltado pela nossa experiência cotidiana, embora saliente "que devemos ser educados desde a juventude a sentir prazer e dor a respeito de objetos corretos; esta é a educação correta"28 (cf. 1104b3-13). Em última instância, se seguimos a leitura de Furley, mesmo no primeiro estágio não podemos agir diferentemente, dado o papel da educação como fator incontornável na formação do caráter. Neste sentido, então, não podemos atribuir alguma liberdade às ações, pois elas são determinadas pela educação, no primeiro estágio, e pelo caráter, no segundo ${ }^{29}$.

$* * *$

Em um sentido diverso de Furley, temos Richard Sorabji. Em Necessity, cause and blame, ele sustentará uma concepção própria acerca do indeterminismo em Aristóteles, onde procura excluir a necessidade, preservando a causalidade, negando peremptoriamente que, no âmbito da ação, Aristóteles possa ser, mesmo remotamente, acusado de determinista. Esta concepção, obviamente, exclui uma visão determinista (SORABJI, 1980, p. 242). É importante ressaltar este ponto, pois Sorabji deixa claro que ele não pode elaborar o mesmo tipo de argumento no que concerne ao processo natural, onde não há possibilidade de esposar uma visão plenamente indeterminista pelo fato de, neste processo, Aristóteles não ter excluído a necessidade causal (Idem).

Exatamente por isso, ele afirma que "eu defini deliberadamente o determinismo em referência não à causação, mas à necessidade” (SORABJI, 1980, p. ix), pois, ao negar que as ações voluntárias sejam necessárias o tempo todo, ele não quer afirmar a possibilidade de que algo possa ser considerado não causado (p. xi), isto é, que exista uma quebra na causação. Assim, ele tenta restringir as teses indeterministas mais radicais preservando, no âmbito das ações, a causalidade, mas excluindo a necessidade (p. xii).

A falha na necessitação, então, contrariamente a ausência da mesma na causação, é o que sutilmente distingue a posição indeterminista de 
Sorabji, na medida em que as ações não devem ser vista como necessitadas o tempo todo. Essa visão parte do pressuposto que Aristóteles não tem em mente o fato de que nossos atos já estejam fixados quando deliberamos (SORABJI, 1980, p. 233), já que no livro III da EN ele argumenta que nossa deliberação não se dá sobre o necessário, mas sobre o que pode ser de outro modo, o que serve, indistintamente, para a ação virtuosa, realizada através de um processo de escolha deliberada. Tal perspectiva torna-se evidente pela ideia de que "a ação plenamente deliberada não é o único tipo de ação existente. As ações voluntárias formam uma classe mais ampla, como ele explana em EN 1111 b8 e EE 1226b30" (SORABJI, 1980, p. 233). Ora, para Sorabji, claramente as ações voluntárias não são necessitadas, já que estas são explicitadas por referência a dois conceitos-chave na ética aristotélica, quais sejam, "o que depende de nós” (to eph' hêmin), e a origem interna (archê en hêmin) de nossas ações: tais conceitos são refratários a qualquer argumento a favor da necessidade (SORABJI, 1980, p. 233-234).

A relação da voluntariedade das ações, e sua relação com a origem interna das ações e com o que depende de nós, acaba por excluir qualquer processo de necessitação do âmbito da ação ${ }^{30}$. Dependerá do agente fazer $x$ ou $\sim x$, "uma possibilidade dual" (p. 234), o que impõe uma quebra no que tange, como mencionado, à necessitação. Mas a impossibilidade da necessitação todo o tempo não se aplica à causação ${ }^{31}$, a despeito do que Sorabji denomina "princípio desafortunado" encontrado na Metafísica E 3 , que sustenta que o que é causado é necessitado (p. 238), princípio que teria sido esquecido por Aristóteles ${ }^{32}$.

Observando as posições de Furley e de Sorabji, poderíamos propor, em termos gerais, duas posições: (i) em Furley, há a negação radical da possibilidade de agir contrariamente ao caráter formado, o que impossibilitaria qualquer defesa, ou simples alusão, à possibilidadade de mudança de caráter, o que parece estar em conformidade com a passagem citada no texto (EN III 7), onde há a afirmação de Aristóteles de que uma vez injusto e intemperante, sempre injusto e intemperante; em (ii) Sorabji, admitida a hipótese da quebra da necessitação, podere-se-ia levantar a hipótese de que, ao menos, o bom poderia agir mal, teria esta capacidade, o que transparece nos Tópicos ${ }^{33}$ a seguinte afirmação: "pois até mesmo Deus e o homem bom (spoudaios) são capazes de fazer coisas más, mas isto não é o seu 
caráter; pois é sempre a respeito de sua escolha (proairesin) que os homens maus são assim chamados", o que parece ser corroborado na ENV 4:

"Não faz diferença se um homem bom (epieikês) tenha defraudado um homem vil (phaulos) ou que um homem vil tenha defraudado um homem bom, ou se o adultério foi cometido por um homem bom ou um homem vil. O que importa, ao contrário, é o dano cometido, e a única coisa que a lei considera, tratando as pessoas com igualdade, é se uma pessoa cometeu uma injustiça da qual a outra foi vítima, se uma causou um dano do qual a outra foi vítima" (1132a2-6) ${ }^{34}$.

Vimos que Alexandre de Afrodísia, mesmo tentando salvar Aristóteles na questão da responsabilidade moral, também sustentou a tese de que, após a constituição da disposição de caráter, não é mais possível agir contrariamente ao mesmo. Logo, os três comentadores de Aristóteles, de um modo ou outro, acenam para a impossibilidade da mudança de caráter, até mesmo Sorabji, na sua visão particular acerca do indeterminismo em Aristóteles.

Nos restaria Teofrasto, no relato de Simplício, quando o primeiro afirma com incredulidade, que Aristóteles nunca aceitaria a suposição de que a virtude, e podemos entendê-la aqui como uma disposição de caráter, pudesse ser perdida, e, por analogia, acrescento, o vício. Há evidências textuais em Aristóteles para sustentar que as disposições de caráter virtuosas e viciosas pudessem sofrer alteração? E em que medida?

\section{$* * *$}

No capítulo 10 das Categorias, o enfoque é menos severo no que concerne à mudança e à disposição de caráter, já que a posse de uma hexis não implica a impossibilidade de agir diferentemente ou mesmo mudar de disposição de caráter. Ao discorrer sobre os contrários, e sobre a possibilidade de mudança de um contrário em outro, "ao menos que um contrário pertença a algo por natureza, por exemplo, para o fogo, o fato de ser quente" (Cat. 13a19-20), Aristóteles sustenta que é tranquilamente plausível afirmar que um contrário pode transformar-se (mudar) em outro, pois quem está saudável pode ficar doente, o branco pode transformar-se 
em preto, o que está frio pode tornar-se quente, “e é possível que de bons (spoudaios) nos tornemos maus (phaulos), e que de maus nos tornemos bons" (Cat. 13a22-23).

Essa asserção é significativa, pois retira da disposição seu caráter absoluto. O bom pode tornar-se mau, e o mau, bom. As linhas seguintes (Cat. 13a22-27) confirmam a argumentação, dado que Aristóteles concede que o mau pode progredir moralmente, desde que identifique propósitos que o levem a tal melhoria. O progresso pode ser pequeno, mas a partir do instante que este pequeno progresso é feito, nada impede que tenhamos um progresso maior, ou mesmo mudar completamente de disposição de caráter: "Pois tornamo-nos sempre mais aptos a mudar facilmente em vista da virtude, por menor que terá sido o progresso feito ao começar, de modo que é verossímil que se possa progredir ainda mais. E quando isto se reproduz constantemente, passamos completamente ao estado oposto, se não somos impedidos pelo tempo" (Cat. 13a27-31). A leitura desta passagem sugere algo aparentemente evidente: o virtuoso pode tornar-se vicioso, e o vicioso pode tornar-se virtuoso.

Podemos aplicar isto à citação do bom (epieikês) que defraudou o vil, bem como a dos Tópicos (spoudaios)? De que modo poderíamos fazer isto? Provavelmente estabelecendo uma simetria entre a passagem das Categorias com as duas passagens em questão.

É necessário ressaltar que a passagem das Categorias acena para um lento, mas possível, processo de reforma moral, levando o phaulos paulatinamente a uma mudança drástica do ponto de sua persona moral, de mal passando a bom. O mesmo poderia ser afirmado do spoudaios dos Tópicos, e do epieikês da ENV. Embora não seja seu caráter, o spoudaios poderia fazer o mal, do mesmo modo que o epieikês poderia defraudar o vil, embora este não seja o seu caráter. O phaulos começou lentamente, conforme vimos, a agir contrariamente ao seu caráter, até a sua conversão moral: por que não podemos raciocinar inversamente no que concerne ao spoudaios e ao epieikês, que tomo aqui como sinônimos, - e não arbritariamente, pois temos uma simetria de usos que não pode desconsiderar a leitura que privilegia a sinonímia entre os dois -, da mesma forma que podemos ampliar o raciocínio para o agathos da passagem citada na nota 35 do presente texto? Logo, é razoável aceitar que, embora não seja o seu caráter, a prática reiterada de ações más pode levar ao virtuoso (spoudaios, 
epieikês, agathos), lentamente, mas talvez inexoravelmente, ao mesmo fim do phaulos, qual seja, a mudança em sua disposição de caráter.

O problema é que, exceto na passagem 1165b13-14 da EN, e mesmo assim lida de um modo que não é carente de polêmica, o restante da $E N$ parece não apresentar uma evidência textual especialmente clara acerca da possibilidade do virtuoso no sentido pleno ser vítima de uma queda ou decadência mora ${ }^{35}$. Contrariamente, a possibilidade da reforma, ou conversão moral, tal qual aparece nas Categorias, é mencionada na passagem 1152a28-30, onde se concebe que o acrático é passível de cura. Deste modo, podemos encontrar uma forte semelhança entre esta passagem da ENVII e a das Categorias 10, já que a reforma moral é expressa de maneira absolutamente translúcida. Mesmo os céticos, que renegam qualquer utilização das Categorias para resolver problemas do corpus ético, poderão perceber a identidade de sentido dos dois textos. Independentemente das dificuldades de definir claramente uma hipótese que permita a ideia de uma queda moral, a reforma moral fica evidenciada a partir de uma leitura atenta da argumentação aristotélica na $E N$, mesmo que deixássemos de lado o texto das Categorias, bem como parece razoável supor, utilizando este texto, uma simetria aceitável entre o phaulos que se regenera moralmente, em um lento progresso, e o spoudaios (eipeikês, agathos), que pode agir mal - embora não seja, na origem, seu caráter -, e ao agir mal perpretar um lento processo de degradação moral.

\section{Retomando duas passagens vexatórias}

Obviamente a complexidade do tema nos obriga a lançar mão de analogias e simetrias para estabelecer uma argumentação coerente que permita encontrar, ou mesmo apenas indicar, uma solução para o problema. Para isto, é necessário retomar as duas passagens extremamente dificeis para estabelecer uma tese positiva no que concerne à possibilidade da mudança de caráter em Aristóteles. São elas:

(a) EN1114a9-21, a famosa passagem mencionada anteriormente neste texto, que indicaria a absoluta fixidez da disposição de caráter após a sua aquisição, e exemplificada nos casos do injusto e e do intemperante, que 
uma vez injustos e intemperantes, não poderiam mais deixar de sê-lo; e (b) EN1129a11-15, onde a pressuposta incontornabilidade da disposição de caráter é dramatizada, ao afirmar-se que uma mesma disposição não pode gerer efeitos contrários

A primeira passagem (a) parece não deixar nenhuma dúvida quanto à impossibilidade de agir contrariamente à disposição de caráter adquirida. Parece não deixar dúvida, mas se lermos as linhas anteriores, ao menos uma afirmação e um exemplo apresentados por Aristóteles chamam a atenção:

"se alguém pratica as ações pelas quais se tornará injusto, não ignorando, ele é voluntariamente injusto. Todavia, isto não significa que, sendo injusto, cessará de o ser (i) quando quiser e ficará justo; tampouco o doente cessa de estar doente e fica são quando quer. Contudo, se assim ocorre que leva uma vida de modo acrático e não obedece aos médicos, adoecerá voluntariamente. (ii) Por um lado, era-lhe, em um momento, possivel de não adoecer; tendo dissipado a saúde, não the é mais possivel, assim como não é mais possível àquele que lançou uma pedra recuperá-la; no entanto, estava em seu poder o lançar, pois o princípio estava nele. Similarmente, era possível ao injusto e ao intemperante não se tornarem tais no início, e por isso o são voluntariamente. Porém, aos que se tornaram injustos ou intemperantes, não lhes é mais possível não o serem”.

Quanto a (i), não me estenderei, pois remeto à excelente leitura do ponto feita por Di Muzio (2000), a qual acolho sem ressalvas, quando fica claro, tal como aparece nas Categorias, que não basta um ato do querer para reformar-se moralmente, na medida em que outras condições são requeridas. No que se refere a (ii), o interessante é a relação entre o exemplo da doença e o processo que atinge o injusto e o intemperante, pois são, literalmente, conforme Aristóteles, similares. Como podemos, razoavelmente, comparar o exemplo (a analogia) da doença com o caso do injusto e intemperante condenados, aparentemente, a sê-lo ad infinitum? Bem, posso levar uma vida de excessos que, eventualmente, pode comprometer a minha saúde, restringir as minhas atividades, mas isto não tem a premência definitiva que alguns buscam atribuir aos dois viciosos. Dissipei minha saúde, não posso, por mim mesmo, evitar o fato de que fui a causa do estado em que me encontro, que não ficarei são por um ato do querer, 
mas precisarei de alguém que buscará reestabelecê-la, de um médico, que me orientará e indicará o que devo fazer para não recair na mesma armadilha em que me meti, e me manter saudável. Ora, seguindo prescrições externas poderei novamente seguir em frente, superar a doença, e retomar minhas atividades e fazer o necessário para me manter são. Se, como observa Aristóteles, a analogia da doença é similar ao problema do injusto/ intemperante, estes poderão, não por um ato de querer, mas identificando propósitos externos, a partir de referências externas, encetar um processo de progresso moral, até à reforma. A analogia que trata como similares a doença e o injusto/intemperante, para fazer sentido, somente poderia ser entendida desta forma, o que retiraria a danação eterna a que estariam submetidos o injusto e o intemperante.

Logo, é possível desdramatizar a passagem, e, também, livrar Aristóteles de sérios embaraços a respeito de sua concepção de responsabilidade moral. Uma tal leitura também torna mais tangível e inteligível a passagem que abre EN III 7, que mostra que depende de nós agir, como de não agir, do mesmo que depende de nós o sim e o não (1113b6-14), pois "somos senhores de nossas ações do início ao fim, desde que conhecedores das circunstâncias; de outro, somos senhores do início das disposições, mas o acréscimo caso a caso não é distinguível, assim como ocorre nas doenças. Porque, porém, estava em nosso poder nos servir assim ou não assim, por esta razão são voluntárias" (1114b31-1115a3). O que coere perfeitamente com EE 1226a26-28, onde surge a seguinte afirmação:“(...) o que tem a possibilidade não somente de ser e não ser, mas ainda tem a possibilidade de fornecer um objeto de deliberação aos homens (...) depende de nós que o façamos ou não" 36 .

Quanto à (b), há a a forte afirmação de que uma mesma disposição não pode gerar efeitos contrários. Lida sem matizes, a impressão que emerge é a absoluta impossibilidade de que uma vez adquirida determinada disposição de caráter, esta assume um estatuto de incontornabilidade, em função de sua fixidez. Mas se confrontarmos esta passagem com a que estabelece a distinção da disposição (hexis) com o estado (diathesis), creio que poderíamos ter uma leitura mais souple desta pretensa incontornabilidade:

"Tais são os conhecimentos científicos e as virtudes; com efeito, estimase que o conhecimento científico está entre as disposições (hexeis) mais estáveis e dificeis de modificar (...) O mesmo ocorre com a virtude: assim, 
estima-se que a justiça, a temperança e cada uma das qualidades deste tipo não são fáceis de mudar ou modificar (...) enquanto chamamos estados (diatheseis) as qualidades que são fáceis de mudar e que se modificam rapidamente". ${ }^{37}$

Nada semelhante a uma fixidez de tal modo rígida retiramos da passagem. Sim, a virtude não é fácil de ser modificada, mas isto não deve causar surpresa nos leitores da ética aristotélica. O que o texto deixa transparecer é que, em relação ao estado, a disposição tem um aspecto de maior estabilidade, não que seja absolutamente inflexível. Aristóteles está realçando algo que deve ser central na sua ética, a estabilidade das disposições, pois a virtude não pode estar sujeita às vicissitudes mais ou menos triviais com as quais o agente moral se defronta ao longo de sua vida. Por isto, ele utiliza um tom dramático, para realçar os contornos desejados de uma hexis. Se assim não o fosse, dificilmente seria crível o que Aristóteles observa na sua Metafísica: "cada uma das coisas que são acompanhadas de razão são igualmente capazes de efeitos contrários" $(1046 \mathrm{~b} 5)^{38}$.

No De Interpretationte, Aristóteles, como que antecipando o Argumento Preguiçoso $(\operatorname{argos} \log o s)^{39}$, afirma:

"Estas são, dentre outras, as consequências absurdas às quais chegamos ao admitir que para todo conjunto constituído de uma afirmação e de uma negação contraditórias (sobre universais falados universalmente ou sobre particulares), necessariamente uma é verdadeira e a outra falsa, e que nada nas coisas em devir é segundo qualquer um dos dois membros da alternativa, e que tudo é e ocorre por necessidade. Em consequência, não haveria necessidade de deliberar, nem de se preocupar, uma vez admitido que se nós fazemos isto, isto ocorrerá, e que se nós não fazemos isto, isto não ocorrerá”.

Ora, se tudo ocorre por necessidade, nossa deliberação seria vã e fútil, na medida em que nada dependeria de nós, o que contrasta com as diversas passagens citadas neste texto. E nossa deliberação vem acompanha de razão, o que permite a aplicação imediata do argumento relativo à potência dos contrários no processo refente às nossas escolhas, ou seja, a possibilidade de escolher $x$ ou $\sim x$, condição de necessidade para uma possível mudança de caráter, embora como ressaltamos, a evidência de mudança é 
mais factível se temos em mente a ideia de reforma ou conversão moral, já que o texto aristotélico é muito menos generoso à tese de queda moral.

No que concerne, então, à decadência ou débâcle moral, o texto aristotélico apresenta poucas evidências para tal, salvo a passagem do livro IX da Ética Nicomaquéia, onde o amigo bom torna-se mau, ou analogias e sinonímias entre passagens que estabelecem uma proximidade entre as diferentes figuras morais, como o spoudaios, o epieiekês e o agathos, sinonímias e analogias que, talvez, possam ser lidas em termos de queda moral, circunstancial ou paulatina. Mas, para o oposto, a reforma ou a conversão moral, ao menos do incontinente, as passagens permitem uma fundamentação mais sólida, mesmo que, por algum motivo, descartemos as obras não éticas de Aristóteles, desde que para tal descarte os objetores ofereçam boas razões.

${ }^{1}$ Segundo D. Amand (1945, p. 35), este é o caso, pois a repetição de atos conforme à virtude cria uma "constituição moral", um caráter fixo e estável, que o homem não pode mais transformar.

2 1129a11-15.

3 “O que é verdade das ciências e potências não o é para os hábitos, pois os contrários pertencem à mesma potência (por exemplo, branco e preto à visão), e à mesma ciência (saúde e doença à medicina). Mas no que concerne aos hábitos, coisas contrárias não são referidas a eles" (Non enim eodem modo se habet in habitibus, sicut in scientiis et potentiis. Contraria enim pertinent ad eamdem potentiam, sicut album et nigrum ad visum, et ad eamdem scientiam, sicut sanum et aegrum ad medicinam. Sed habitus contrarius non se habet ad contraria sibi. Cf. Tomás de Aquino, Sententia Ethic., lib. 51.1 n. 6). No prosseguimento, Tomás se refere ao exemplo de Aristóteles: a partir da saúde não posso produzir algo contrário à saúde, mas somente coisas saudáveis (1129a15-17).

${ }^{4}$ Cf., também, Sobre a memória e reminiscência, 452a 27-28: "pois o hábito agora assume o papel da natureza" ("hôsper gar phusis êdê ethos").

${ }^{5}$ Esta pretensa fixidez e estabilidade do hábito e da disposição pode ser nuançada. Segundo P.-M. Morel: "o hábito é, finalmente, como uma natureza. Mas "ele nunca chega a igualá-la, e sua origem artificial parece confiná-lo em uma ordem que não seria aquela da continuidade dos movimentos propriamente naturais" $(1997,136)$, ou seja, “o que se produz pelo hábito não possui jamais a regularidade do que se produz por natureza" (1997, p. 136, n. 16); “o hábito muda mais facilmente que a natureza”. Cf. Morel, ver também Magna Moralia 1203b30-32:"as condutas naturais são mais difíceis de corrigir do que as nascidas do hábito".

${ }^{6}$ J. Hintikka (1977, p. 39) afirma que "em vista do que vimos não é surpresa ver a psicologia da ação humana [de Aristóteles] ser caracterizada por competentes comentadores, como é o 
caso de D. J. Allan (1955, p. 333), como determinista”. Exatamente por isto, Hintikka afirma que "não realizei plenamente a natureza da mais importante tentativa de desembaraçar-se de seu auto-infectado determinismo" (1977, p. 8). Por isto é sugestivo que ele escreva, ao se referir aos fatos da natureza humana, que se o homem pode agir, e não é impedido de fazê-lo, na medida em que conhece o bem, deve agir imediatamente (1147a30-31): este é o tipo de suposição que encaminha Aristóteles, de forma temerosa, em direção ao determinismo (p. 52), pois o conhecimento do bem implica desejo e ação.

7 Éthique à Nicomaque (traduction et présentation par R. Bodéüs). Paris: GF Flammarion, 2004 , p. 460, n. 2. A dificuldade maior para Bodéüs identificar o virtuoso somente com o spoudaios é que Aristóteles não parece realmente estabelecer esta restrição, pois, por exemplo, em 1104b30-1105a1, o agathos é entendido em termos de virtuoso: "Como são três os objetos de busca - o belo, o proveitoso e o agradável - e três os contrários - o feio, o danoso e o penoso -, o homem bom é correto e o homem perverso é incorreto a respeito de todos eles, mas sobretudo a respeito do prazer, pois este é comum aos animais e acompanha a tudo o que cai na rubrica busca, pois o belo e o proveitoso são manifestamente prazerosos". O contexto todo deste capítulo (II 2) indica que se está falando do virtuoso, e este é sinônimo de homem bom (agathos). Irwin traduz por "virtuoso", o que é significativo, pois permitiria mostrar que o homem bom não seja outro que o virtuoso em sentido pleno, o homem verdadeiramente bom, contrariamente à interpretação de Bodéüs.

8 Theophrastus of Eresus: Sources for his Life, Writings Thought and Influence, Fr. 462.

${ }^{9}$ Idem, Fr. 463.

${ }^{10}$ Idem, Fr. 495.

${ }^{11}$ Idem, Fr. 497.

${ }^{12} \mathrm{O}$ que se tem em mente é a relação entre Teofrasto e os peripatéticos, em comparação com a rejeição de Aristóteles à teoria platônica das formas (Theophrastus of Eresus: Sources for his Life, Writings Thought and Influence, p. 325).

${ }^{13}$ Em oposição a Zenão de Cítio, o estoico.

14 Theophrastus of Eresus: Sources for his Life, Writings Thought and Influence, Fr. 499.

15 XXVI, 196.25-30.

${ }^{16}$ Sobre "o que depende de nós" em Alexandre, além do De Fato, ver também Ethical Problems 29, e Mantissa XXII e XXIII.

${ }^{17}$ XXVI, 197.1-2.

18 XXVII, 197.3-6.

${ }^{19}$ XXVII, 197.12.

${ }^{20}$ XXVII,199.3-4.

${ }^{21}$ XXVII,198.24.

${ }^{22}$ XXIX,199.25-30. 
23 ZINGANO (2007, p. 3).

${ }^{24}$ Em uma passagem do seu De Fato, Cícero afirma o seguinte:" Ac mihi quidem videtur, cum duce sententice fuissent veterum philosophorum, uma corum, qui censerent omnia ita fato fieri, ut id fatum vim necessitatis aferrent, in qua sententia Democritus, Heraclitus, Empedocles, Aristoteles fuit (Duas opiniões partilhavam os antigos filósofos: segundo uns tudo o que acontece é submetido ao destino, ao qual eles dão força de necessidade, tal era a opinião de Demócrito, Heráclito, Empédocles e Aristóteles)". Segundo Octave Hamelin (1978, p. 36), é surpreendente observar a inclusão de Aristóteles como um defensor da doutrina da fatalidade universal. Esta passagem é discutida, e alguns pretendem que não seria o caso de Aristóteles, e sim de Anaxágoras. Mas é necessário ressaltar que os peripatéticos alexandrinos acreditavam que a questão do destino era importante, pois tinha ligação inequívoca com o problema da responsabilidade moral (HAMELIN, 1978, p. 12).

${ }^{25}$ Cf. EN1114a3ss.

$261150 \mathrm{~b} 32-5$.

${ }^{27}$ Furley fala de um comando da mente para as ações que são voluntárias, em conformidade com a disposição específica. O mesmo ocorreria com a virtude moral, entendida como uma disposição de escolher de certo modo "e não como uma disposição para agir de certo modo (...) a escolha é determinada pela disposição; uma vez fixada a disposição, um estímulo de determinado tipo produzirá uma reação característica, não uma fortuita” (FURLEY, 1977, p. 58-59).

${ }^{28}$ No sentido de "treinamento moral" (FURLEY, 1977, p. 58).

${ }^{29}$ Conforme bem observou Carlo Natali (2004, p. 181), a interpretação de Furley acaba por tomar uma "forma estoicizante", que não é uma característica que podemos atribuir apenas a Furley, mas que é bastante evidente na sua argumentação, pois "ele coloca a existência de duas cadeias causais determinadas, a que é constituída pela série de eventos do mundo exterior, que provoca a percepção sensível, e a que é constituída pela história pessoal do agente, que determina o caráter. Quando as duas cadeias se encontram, o resultado só pode ser uma ação necessária”.

${ }^{30}$ Cf., por exemplo, EE 1225b8-10: "o que depende de um homem não fazer, e ele o faz mesmo assim, sem estar na ignorância e agindo por si mesmo, é necessariamente voluntário".

${ }^{31}$ A recusa à possibilidade de quebra na causação o faz criticar posições como as de Ross e Furley que defendem a ideia de 'fresh starts' em Aristóteles. Ross afirma: "There is, however, a third element in Aristotle's notion of accident which seems to imply objective contingency, and not merely contingence relative to the present imperfection of our knowledge. In the history of the world there are fresh starts which are not the determinate result of anything that has preceded (...) The reason is that there is an arch $\hat{e}-$ a genuine starting point for futures events - in human deliberation and action" (ROSS, 1924, vol. 1, p. 1xxxi).

32 Sorabji sustenta que tal princípio não se aplica, e é até mesmo contraditado em outras passagens (Necessity,cause and blame, cap. III). Esta afirmação de Sorabji é rejeitada fortemente na resenha escrita por G. FINE, “Aristotle on determinism”. The Philosophical Review, XC (4), 1981, p. 561-579. Tratarei deste ponto específico em outro texto.

33 Top. 126a34-36.

doispontos, Curitiba, São Carlos, vol. 10, n. 2, p.291-313, outubro, 2013 
${ }^{34}$ Em um um sentido mais radical, temos a EN IX, 1165b13-14, onde Aristóteles indaga, ao tratar da amizade, se alguém que aceita um amigo porque ele é bom (agathon), mas que se torna perverso (mokhthêros) deve ainda permanecer amigo deste último? O problema aqui, como na passagem citada, é se podemos traduzir epieikês e agathon por virtuoso, na medida em que, usualmente, o termo usado para designar o virtuoso é spoudaios, que, lembremos, aparece na passagem dos Tópicos supracitada como tendo a dunamis de fazer o mal, embora não seja o seu caráter.

${ }^{35}$ A exigência de evidência textual de uma pretensa queda moral ou reforma moral cairia por terra caso se interprete figuras morais tais como o phronimos (prudente), impermeável ao vício, e o akolastos (intemperante), incorrigível, como algo que não pode ser encontrado no mundo em que vivemos: “(...) I think, that the picture of a perfect phronimos who never acts badly, or the totally akolastos who cannot but act badly, are just ideals who are actually never to be found in our real world" (DESTRÉE, 2011, p. 302). Bem, se esta leitura está correta, restringiríamos todas as análises da possibilidade de mudança de caráter ao acrático e ao encrático.

36 “(...) é evidente que nem tudo é, ou acontece, por necessidade, mas para algumas coisas elas se produzem de maneira indeterminada [a ação] e que, então, a afirmação ou a negação, não são mais verdadeiras uma que a outra, enquanto que, para algumas outras, uma das duas é mais verdadeira a maior parte das vezes [a natureza], embora ocorra que a outra aconteça e não ela “(De Int.19a18-22).

37 Cat., 8b29-36.

38 Donini (1989, p. 82) é claramente contrário ao uso desta passagem por considerá-lo ilegítimo referir-se ao texto da Metafísica para demonstrar que a ação moral estaria sempre aberta aos contrários, pois, segundo ele, a Metafísica não se preocupa nunca com questões relativas à ação moral. É também o caso de Hardie, que salienta: "I know of no authority for this use of the Aristotelian expression 'capacity for opposites' [para o caso da disposição que é a virtude moral]. It has nothing to do with the use of the expression found, as we have seen, in Metaphysics ๑” (HARDIE, 1980, p. 102).

${ }^{39}$ A formulação do argos logos, tal qual o encontramos em Cícero (De Fato 28-30), é a seguinte: "Se é teu destino te curar desta doença, te curarás, quer chames o médico ou não; do mesmo modo, se não é teu destino te curares desta doença, não te curarás, quer chames o médico ou não. Uma e outra coisa é o teu destino. Por conseguinte, não há interesse algum em chamar o médico". Crísipo rebate o argumento estabelecendo a distinção entre eventos simples e complexos, e estes últimos são co-destinados: "confatalia ille appellat".

\section{Referências bibliográficas}

ALEXANDRE DE AFRODÍSIA. 1990. Ethical Problems (trad.). Cornell: Cornell University Press. 2003. On Fate (text, traduction and commentary R.W. Sharples). London: Duckworth. 
ALLAN, D. J. 1955. The practical syllogism. In: Autour d'Aristote. Louvain: PUL, p. 325-340.

AMAND, D. 1945. Fatalisme et liberté dans l'antiquité grecque. Louvain: Bibliothèque de l'Université.

ARISTÓTELES. 1924. Metaphysics (a revised text with introduction and commentary by W. D. Ross). Oxford: Clarendon Press, 2 vols.

1942. Ethica Nicomachea (I. Bywater, ed.). Oxford: Oxford Classical Texts.

.1949. Categoriae et Liber De Interpretatione (L. Minio - Paluello, ed.). Oxford: Oxford Classical Texts.

1958. Topica et Sophistici Elenchi (W.D. Ross, ed.). Oxford:

Oxford Classical Texts.

1964. Analytica Priora et Posteriora (W.D. Ross, ed.). Oxford:

Oxford Classical Texts.

1990. Magna Moralia. Harvard: Loeb Classical Library.

1991. Ethica Eudemia (R. R. Walzer e J. M. Mingay, eds.).

Oxford: Oxford University Press.

1999. Nicomachean Ethics (translated with introduction, notes, and glossary, by T. Irwin). 2. ed. Indianapolis/Cambridge: Hackett.

.2008. Aristóteles. Ethica Nicomachea I 13 - III 8. Tratado de

Filosofia Moral (Introdução, tradução e comentário de Marco Zingano). São Paulo: Odysseus.

DESTRÉE, P. 2011. Aristotle on responsibility for one's character. In: Moral psychology and human action in Aristotle (M. Pakaluk; G. Pearson, eds). Oxford: Oxford University Press.

DI MUZIO, G. 2000. Aristotle on improving one's character. Phronesis, 45 (3), p. 205-219.

DONINI, P. L. 1989. Ethos. Aristotele e il determinismo. Alessandria:

Edizioni dell Orso. 
FORTENBAUGH, W. W; HUBY, P. M.; SHARPLES, R. W.; GUTAS, $\mathrm{D}$ (ed e trad.). 1993. Theophrastus of Eresus: Sources for his Life, Writings Thought and Influence. Part two (Psychology, ethics, religion, politics, rhetoric and poetics, music, miscellanea). Leiden-New York-Köln: E.J. Brill.

FURLEY. D. J. 1977. Aristotle on the voluntary. In: Articles on Aristotle: ethics and politics (J. Barnes, M. Schofield and R. Sorabji, eds.). v. 2. London: Duckworth, p. 47-60.

HAMELIN, O. 1978. Sur le De Fato. Paris: Éditions de Mégare. HARDIE, W. F. R. 1980. Aristotle's ethical theory. 2.ed. Oxford: Clarendon Press.

HINTIKKA, J. 1977. Aristotle on modality and determinism. In: Acta Philosophica Fenicia, v. 29, n. 1.

MOREL, P. -M. 1997. L'habitude: une second nature? In: Aristote et la notion de nature. Enjeux épistémologiques et pratiques (Morel, P.-M. ed.). Bourdeaux: Presses Universitaires de Bourdeaux, p. 131-148.

NATALI, C. 2004. L'action efficace. Études sur la philosophie de l'action d'Aristote. Louvain-la-Neuve: Éditions Peters.

SORABJI, R. 1980. Necessity, cause, and blame. London: Duckworth. ZINGANO, M. 2007. Ação, caráter e determinismo psicológico em Alexandre de Afrodisia. 0, 1 (1), p. 1-16. 